\title{
PELATIHAN MANAJEMEN PEMELIHARAAN IKAN CUPANG SEBAGAI IKAN HIAS YANG BERPOTENSI MENINGKATKAN PENDAPATAN MASYARAKAT
}

\section{TRAINING OF MANAGEMENT FIGHTING FISH (Betta sp.) AS A POTENTIAL FISHERY INCREASING COMMUNITY REVENUE}

\author{
Fazril Saputra $^{1^{*}}$, Teuku Reza Efianda ${ }^{1}$ \\ ${ }^{1}$ Program Studi Akuakultur, Fakultas Perikanan dan IImu Kelautan, Universitas Teuku Umar \\ *Korespondensi: fazrilsaputra@utu.ac.id
}

\begin{abstract}
ABSTRAK
Pengabdian ini bertujuan untuk memberikan pelatihan manajemen pemeliharaan ikan cupang (Betta sp.) yang baik dan benar sesuai dengan SNI ikan cupang hias kepada masyarakat Desa Paya Peunaga, Kecamatan Meureubo, Kabupaten Aceh Barat. Permasalahan yang dihadapi saat ini adalah data statistik Kabupaten Aceh Barat dalam angka tahun 2017 menunjukan bahwa banyak masyarakat memiliki usia produktif di Desa Paya Peunaga, Kecamatan Meureubo, namun tidak dibarengi oleh lowongan pekerjaan sehingga menyebabkan banyaknya pengangguran pada usia produktif. Solusi yang ditawarkan dari pengabdian ini adalah memberikan keterampilan tambahan kepada masyarakat di Desa Paya Peunaga, Kecamatan meureubo untuk dapat memanajemenkan pemeliharaan ikan cupang yang baik dan benar sesuai dengan SNI ikan cupang hias. Metode pengabdian adalah diskusi dan praktek langsung cara membudidaya ikan cupang (Betta sp.) yang baik dan benar. Pelaksanaan kegiatan pengabdian kepada masyarakat meliputi: 1) diskusi dan sosialisasi ikan cupang hias (Betta sp.) yang berpotensi meningkatkan pendapatan masyarakat dan 2) pelatihan manajemen ikan cupang hias yang baik dan benar sesuai SNI ikan cupang hias. Hasil yang diperoleh dari pengabdian adalah masyarakat sangat antusias untuk membudidayakan ikan cupang hias (Betta sp.) dan mengharapkan agar program pengabdian kepada masyarakat ini dapat terus dilaksanakan untuk memberikan pendampingan kepada masyarakat di Desa Paya Peunaga, Kecamatan Meureubo, Aceh Barat.
\end{abstract}

Kata kunci: Ikan cupang, Paya Peunaga, Pendapatan masyarakat, Pelatihan

\begin{abstract}
Dedication to provide maintenance management training fighting fish (Betta sp.) the good and completely in accordance with SNI fighting fish to the community PayaPeunaga, Meureubo sub-district, West Aceh District.The problem faced today is the statistics of West Aceh Regency in 2017 figures indicating that many people have a productive age in PayaPeunaga Village, Meureubo Sub-district, but not accompanied by job vacancies, causing unemployment at productive ages. Solution offered from this dedication is to provide additional skill to the community in PayaPeunaga Village, MeureuboSubdistrict to be able to manage the good and correct fighting fish in accordance with SNI of fighting fish.Implementation of community service activities include: 1) discussion and socialization of fighting fish (Betta sp.) that potentially increase the income of the community and 2) good ornamental fighting fish management training according to SNI of fighting fish. Result of the dedication is that the community is very enthusiastic to cultivate fighting fish and hopes that this community service program can be continued to provide assistance to the community in PayaPeunaga Village, Meureubo Sub District, West Aceh.
\end{abstract}

Keywords: Community revenue, Fighting fish, PayaPeunaga, Training

\section{PENDAHULUAN}

Meureubo merupakan Kecamatan yang terletak di Kabupaten Aceh Barat. Kecamatan Meureubo memiliki luas $112,87 \mathrm{~km}^{2}$. Kecamatan meureubo terdiri dari 26 
desa dan 8 dusun. Jumlah penduduk Kecamatan Meureubo pada tahun 2016 adalah 29,689 Jiwa atau 15\% dari populasi penduduk Kabupaten Aceh Barat. Jumlah pencari kerja tertinggi menurut strata pendidikan yaitu strata SMA yaitu sebanyak 638 Jiwa yaitu 410 pria dan 228 wanita. (Aceh Barat Dalam Angka, 2017).

Salah satu desa yang ada di Kecamatan Meureubo adalah desa Paya Peunaga dengan luas wilayahnya $0,04 \mathrm{~km}^{2}$, yang letaknya adalah : 95․ 141-95․30 BT,5․00$5.13^{1} \mathrm{LU}$ dan bila dilihat dari letak geografis desa Paya Peunaga hanya terdiri dari daratan tidak berbukit, tinggi dari permukaan laut adalah 1,5 meter, beriklim tropis dengan ketenggian suhu mencapai $27^{\circ} \mathrm{C}-31^{\circ} \mathrm{C}$, dengan curah hujan yang terbanyak $144 \mathrm{~mm} /$ hari, banyaknya curah hujan $6.000 \mathrm{~mm} /$ tahun. Mayoritas penduduk bekerja sebagai nelayan/pembudidaya, petani/karet, pedagang, buruh dan wiraswasta, hanya sebagian kecil saja yang berprofesi pegawai negeri sipil (Profil Gampong Paya Peunaga Kecamatan Meureubo Kabupaten Aceh Barat, 2012).

Data statistik Aceh Barat dalam angka tahun 2017 menunjukan bahwa banyak masyarakat memiliki usia produktif di Kecamatan Meureobo, namun tidak dibarengi oleh lowongan pekerjaan di Kecamatan Meureobo. Hal ini dibuktikan dengan banyaknya jumlah pencari kerja yang terdata di Dinas Tenaga Kerja dan Mobilisasi Penduduk Kabupaten Aceh Barat.

Banyaknya pencari kerja juga terjadi di Desa Paya Peunaga, padahal jika dilihat dari segi administratif, letak Desa Paya Peunaga, Kecamatan Meureubo sangat cocok untuk melakukan kegatan budidaya perikanan. Namun kegiatan budidaya yang dilakukan belum maksimal, banyak kegiatan budidaya yang potensial belum dilakukan. Jika saja kegiatan budidaya lebih dimaksimalkan maka bisa menurunkan penganguran di Desa Paya Peunaga, Kecamatan Meureubo. Salah satu usaha untuk mengurangi penganguran di Desa Paya peunaga adalah memberikan keterampilan kepada masyarakat seperti pelatihan manajemen pemeliharaan ikan cupang sebagai ikan hias yang berpotensi meningkatkan pendapatan masyarakat.

\section{Tujuan Kegiatan}

Tujuan dari dilakukannya kegiatan pengabdian kepada masyarakat ini adalah mengenalkan ikan cupang hias kepada masyarakat Desa Paya Peunaga dan cara memanajemen budidaya ikan cupang (Betta sp.) yang baik dan benar sesuai dengan SNI budidaya ikan cupang hias (Betta sp.).

\section{METODELOGI}

\section{Tempat dan waktu}

Kegiatan ini telah dilaksanakan pada tanggal 26 Maret 2018 di Desa Paya Peunaga Kecamatan Meureubo, Aceh Barat. Tepatnya di Balai Desa Paya Peunaga Kecamatan Meureubo, Aceh Barat.

\section{Metode pelaksanaan}

Metode pelaksanaan pengabdian masyarakat ini dilaksanakan secara diskusi dan praktek langsung. Pemateri berinteraksi langsung dengan masyarakat pembudidaya ikan dan masyarakat umum. Pemateri memberikan materi dan memberikan contoh langsung cara membudidaya ikan hias cupang yang baik dan 
benar, kemudian masyarakat dapat praktek langsung cara memelihara ikan cupang hias (Betta sp.) yang baik dan benar sesuai SNI ikan cupang hias (Betta sp.)

\section{HASIL DAN PEMBAHASAN \\ Ipteks yang di transfer kepada masyarakat}

Kegiatan pengabdian kepada masyarakat di Desa Paya Peunaga ini dilakukan beberapa tahapan transfer ilmu kepada masyarakat. Adapun transfer ilmu yang diberikan adalah

1. Sosialisasi mengenai keunggulan budidaya ikan cupang sebagai ikan hias yang berpotensi meningkatkan pendapatan masyarakat kepada peserta. Kegiatan ini dilakukan dalam bentuk pemaparan langsung dan diskusi interaktif dengan peserta. Tujuannya adalah untuk menambah pengetahuan dan wawasan mengenai budidaya ikan cupang yang mudah, murah, efektif, efisien dan berkelanjutan.

2. Pelatihan ini juga memberikan bimbingan pembelajaran manajemen budidaya ikan cupang. Manajemen budidaya ikan cupang sangat menentukan pendapatan dan keberhasilan usaha budidaya ikan cupang. Bimbingan pembelajaran manajemen budidaya ikan cupang dilakukan dengan cara mentransfer ilmu kepada masyarakat. Hal ini dilakukan agar peserta menjadi wirausaha yang kompeten dan mampu menjalankan usaha budidaya ikan cupang secara berkelanjutan. Ilmu yang ditransfer kepada peserta yaitu sebagai berikut:

- Manajemen pengadaan benih ikan cupang

Peserta diberi pelatihan cara memilih benih ikan cupang yang sehat dan unggul. Selanjutnya perserta diberi pelatihan langsung metode aklimatisasi yang benar saat penebaran benih dalam wadah budidaya. Hal ini bertujuan untuk meminimalisir kematian ikan cupang karena sering terjadi penanganan benih yang salah saat proses penebaran sehingga ikan cupang mengalami stress.

- Manajemen pemberian pakan ikan cupang

Peserta diberikan pembekalan terkait pemilihan jenis pakan yang tepat untuk pertumbuhan dan perkembangan ikan cupang. Pemberian jumlah pakan yang tepat sangat penting bagi keberhasilan budidaya ikan cupang dikarenakan akan berdampak pada biaya produksi, selain itu pemberian pakan yang berlebih akan berdampak buruk pada kualitas air yaitu peningkatan kadar amonia dan nitrit.

- Manajemen kesehatan ikan cupang

Peserta diberikan sosialisasi berupa materi cara mengidentifikasi jenis penyakit pada ikan cupang, cara pencegahan dan pengobatan dengan bahan alami. Pembudidaya yang mampu mengenali gejala penyakit sangat penting karena dapat melakukan penanganan secara dini sehingga kematian ikan cupang dapat dihindari.

- Manajemen kualitas air ikan cupang

Peserta diberikan pelatihan mengenai pengelolaan kualitas air pada wadah budidaya. Perserta dilatih cara pergantian air dan menjaga kualitas air tetap berada pada kisaran optimal.

- Manajemen reproduksi ikan cupang

Perserta diberikan pelatihan mengenai perkawinan ikan cupang jantan dan betina. Salah satu ciri khusus yang harus dimiliki oleh ikan cupang yang akan kawin adalah ikan hias jantan selain warnanya yang indah, siripnya pun panjang dan 
menyerupai sisir serit, sehingga sering disebut cupang serit. Sedangkan ikan betina warnanya tidak menarik (kusam) dan bentuk siripnya lebih pendek dari ikan jantan. Hal ini penting untuk mengoptimalkan perkawinan ikan cupang. (BSN, 2013 :Fery, 2013 ; Wahyu dewantoro, 2017)

3. Edukasi strategi pemasaran

Strategi pemasaran merupakan salah satu faktor penentu keberlanjutan usaha karena tanpa pemasaran yang tepat usaha akan mengalami penurunan omset. Dalam hal ini peserta dilatih untuk menentukan target pasar dan membentuk mitra kerja dengan beberapa penampung atau agen pembeli ikan hias. Selain itu perserta juga dapat aktif di media sosial untuk mempromosikan ikan cupang hias yang telah berhasil dibudidayakan.

\section{Respons dan umpan balik dari masyarakat}

Respons dari masyarakat sangat antusias untuk mengikuti kegiatan pelatihan manajemen ikan cupang hias ini. Ini dapat dibuktikan dari banyaknya perserta yang hadir untuk mengikuti kegiatan dan keaktifan peserta mengikuti pelatihan manajemen ikan cupang hias ini dengan banyak keinginan untuk ingin tahu dan bertanya serta tidak meninggalkan tempat pelatihan sebelum waktu pelatihan berakhir. Umpan balik dari masyarakat dapat dilihat dari para peserta tertarik untuk membudidayakan ikan cupang hias (Betta sp.) ini secara mandiri.

\section{PENUTUP \\ Kesimpulan}

Kegiatan pelatihan manajemen ikan cupang ini dapat diselenggarakan dengan baik dan berjalan dengan lancar sesuai dengan rencana kegiatan yang telah disusun. Kegiatan ini mendapat sambutan antusias dari masyarakat terbukti dengan keaktifan peserta mengikuti kegiatan pelatihan manajemen ikan hias ini dengan tidak meninggalkan tempat sebelum waktu pelatihan berakhir dan para peserta tertarik untuk membudidayakan ikan cupang ini secara mandiri.

\section{Saran} berikut:

Berdasarkan evaluasi yang telah dilakukan dapat diajukan saransebagai 1. Waktu pelaksanaan kegiatan pelatihan perlu ditambah agar pemateri dapat memonitoring usaha budidaya ikan cupang mandiri yang telah dilakukan oleh peserta.

2. Kegiatan lanjutan berupa pelatihan sejenis selalu dilaksanakan. Pelatihan selalu di selenggarakan secara periodik sehingga dapat meningkatkan keterampilan masyarakat dalam berbudidaya yang baik dan benar sesuai SNI.

\section{UCAPAN TERIMA KASIH}

Ucapan terimakasih diucapkan kepada:

1. Aparatur Desa Paya Peunaga yang telah memberikan izin untuk mengadakan pengabdian kepada masyarakat di Desa Paya Peunaga.

2. Reza Efianda, S.Pi, M.Si dan Fitria Rahmayanti, S.Kel, M.Si yang telah banyak membantu hingga selesainya pengabdian kepada masyarakat ini. 


\section{DAFTAR PUSTAKA}

BPS Aceh Barat, 2017. Aceh Barat Dalam Angka 2017. Penerbit BPS Kabupaten Aceh Barat.

Fery, W.E, 2013, Buku Panduan Lengkap Budidaya Cupang [Diakses tanggal 6 Februari 2018].

Profil Gampong Paya Peunaga Kecamatan Meureubo Kabupaten Aceh Barat, 2012 https://www.old.gsfaceh.com[Diakses 6 Februari 2018].

Wahyu dewantoro, G. 2017.Mengenal Cupang (BettaSpp.) Ikan Hias Yang Gemar Bertarung. Warta Iktiologi Vol 1(1).

Badan Standarisasi Nasional (BSN). 2013. SNI 7777-2013 Produksi ikan cupang hias (Betta splendens). Jakarta: BSN. 


\section{Dokumentasi Kegiatan Pelatihan Manajemen Pemeliharaan Ikan Cupang Sebagai Ikan Hias yang Berpotensi Meningkatkan Pendapatan Masyarakat}
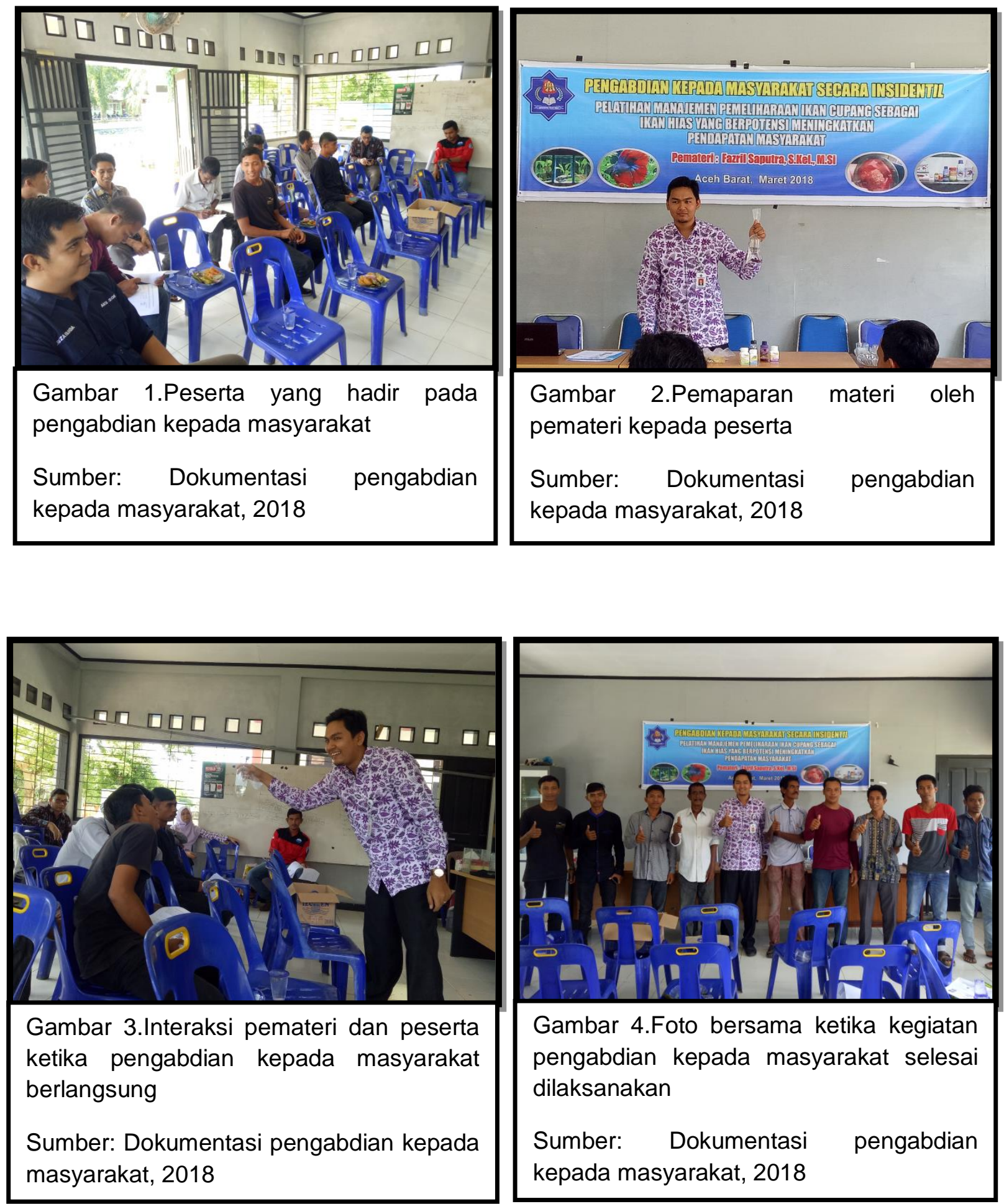